\title{
The Development and Reflection on the Traditional Martial Arts Culture
}

\author{
Zhenghong $\mathrm{Li}^{1, \mathrm{a}}$ and Zhenhua Guo ${ }^{1, \mathrm{~b}}$ \\ ${ }^{1}$ College of Sports Science, Jishou University Renmin South Road 120, Jishou City Hunan Province, \\ China \\ ajsdxgzh@126.com, ${ }^{b} 316225603 @ q q . c o m$
}

Keywords: Martial arts; Martial arts culture; Development; Reflection

\begin{abstract}
Martial arts is an outstanding spiritual creation through the historical choice. As a kind of cultural form, it cnnotations. In this paper, using the research methods of literature, logic reasoning and so on, the interontains the rich cultural copretation of the traditional martial arts culture has been researched. The results show that The Chinese classical philosophy is the thought origin of the martial arts culture. Worshiping martial arts and advocating moral character are the important connotation of Chinese wushu culture. On the pre - qin period, contention of a hundred schools of thought in the field of ideology and culture make martial arts begin showing the cultural characteristics. The secularization of Song-Ming Neo-Confucianism makes martial arts gradually develop into a mature culture carrier. At the same time, this paper also analyzes the external martial arts' impact on Chinese wushu; Western physical education' misreading on Chinese wushu culture; The helpless of Chinese Wushu in In an age of extravagance and waste; The "disenchantment" of Chinese wushu culture in modern society; the condition and hope of Chinese martial arts culture. In view of this, this article calls for China should take great effort to study martial arts, refine, package and promote Chinese Wushu. Otherwise, the ancient and profound martial arts in contemporary Chinese physical education culture can only be " side dishes ", and difficult to be compared with classic elegant main dishes.
\end{abstract}

\section{Introduction}

Chinese wushu belongs to physical education and beyond physical education, and also is a kind of national culture, having close contact with time. To give full play to the role of martial arts in the construction of a harmonious society, it is very necessary to study clearly the harmonious thought Chinese wushu culture contained in the various tectonic levels.

\section{Connotation of Chinese Wushu Culture}

Culture is human spiritual creation, which can spread towards vertical and horizontal way, and can be materialized in a kind of material. Martial arts is an outstanding spiritual creation through the historical choice. The elements of the thoughts and theories made up of martial arts skills, martial arts equipment, martial arts training methods and rules, clothing, sites are all the spiritual creation. What martial arts first shows is materialized in the offensive and defensive action program of life, and then materialized into the symbol record of action program. Through these programs emersion and symbols spread, the longitudinal and transverse radiation, further develop and utilize all kinds of natural force, so as to meet their own survival and development, this is the essence of the martial arts culture. Wushu culture is the product of Chinese traditional culture, is a reflection of China's traditional culture deposition. Self-sufficient farming civilization gave birth to the rich Chinese culture and unique personality traits introversion, harmony, ethical and aesthetic art. Chinese martial arts grows up, evolves, inherits and develops in this national culture, which is guided by the idea in theory, subjected to the restriction on behavior, which has the common features both the traditional culture and its own unique features. As a kind of cultural form it contains the rich cultural connotations [1].

Chinese Classical Philosophy Thoughts Is the Origin of Wushu Culture. The category of Chinese classical philosophy is very large, including many the ideas and theories schools. Holistic 
thinking is a remarkable feature of the Chinese philosophy thinking, it laid the foundation of martial arts fitness theory, formed three aspects of martial arts as a whole thinking: Unity of Man and Nature, Unity of inside and outside, Identity of object and self. Martial arts is the body movement, to achieve the purpose of physical fitness, kungfu practice must comply with the nature, follow the law of nature. Traditional wushu practitioner pays much attention to the change of the four seasons in the nature and human body physiology functions. Based on this, and then, take a different approachs to achieve the goal of training, improve the effect of exercise, realize the unity and harmony between human and nature.

Worshiping Martial Arts and Advocating Oraml Character Are the Important Connotation of Chinese Wushu Culture. So-called morality of Wushu, that is wushu morals, which is moral criterion and moral sentiments that people should abide by in the social activities, including its mind cultivation, moral attitude, mental state and wushu etiquette, throughout the whole process and omnibearing of martial arts such as learning teaching skills from master teachers, learning martial arts, teaching martial arts, using martial arts and so on [2]. As the core of the Chinese wushu ethics, it not only embodies the main body significance of wushu ethics, but also contains the interpersonal relationships of internal order in the martial arts society activities, pay attention to martial arts activities and the order specifications in other social activities. And individuals' morality of wushu has practical value and significance only adapting to the social practice in discipline and regulation of social consensus. Later with the development of era, the connotation of wushu culture becomes increasingly richer in practices, and becomes increasingly more and more mature on the ideological concept, but the basic content has long maintained a relative stability and continuity, the practitioners comply with it in each period.

\section{The Martial Arts Culture Process}

The profound Chinese martial arts has a long history, in the process of thousands of years of development, by the influence and impact of Chinese culture, it has made a simple practical combat art become national treasures with unique cultural characteristics. Like traditional Chinese medicine, traditional opera, calligraphy, Chinese painting, Chinese martial arts is the carrier of Chinese traditional culture, contains rich culture characteristics, which has become consensus in the field of martial arts. How much "culture" composition does wushu have exactly? Why is martial arts a cultural carrier? This paper, firstly based on the historical development of Chinese traditional culture, systematically discusses the evolution process that Chinese wushu has developed into a cultural carrier from a primitive combat technology, and argued the main cultural characteristics that wushu contains. Then, through arguing the relationship between the martial arts and Chinese traditional philosophy, and Chinese classical aesthetics, the paper has explored Chinese martial arts culture.

On the pre - qin period, contention of a hundred schools of thought in the field of ideology and culture makes martial arts begin showing the cultural characteristics. Chinese Wushu, even the martial arts around the whole world, comes into being due to meet the needs of the primitive survival and self-defense. The need for self-defense is produced along with the most basic, the most primitive needs of human. We can even say, even before the human, animals have the most basic instinct. The early martial arts is a survival defensive technology. That the essential differences between Chinese wushu and other martial arts in the world, there is no essential difference between the wushu are that all of them are a bloodthirsty violence technology for human to solve the interests conflict. Experienced in the early qin period, especially during the spring and autumn period, Chinese traditional culture emerged. The spring and autumn period was a cultural prosperous period of hundred schools of thought emerging in Chinese history, the first glorious period of the development of Chinese culture. The prosperity of culture also began to affect the martial arts. Overall, this period martial arts culture has begun to take the following several aspects:

First, the prevalence of "the custom of martial arts" makes Chinese martial arts keep the cultural characteristics "vigorousness". "Strengthen self without stopping, and hold world with virtue" said in 
<the book of changes> [3] is just the Energetic and promising and spiritual portraiture.

Confucius advocated "Brave people aren't afraid", and emphasized "The person who has gentle thing must have defense preparations." [4] Second, the chief cultural performance of Chinese martial arts from the "iron" to "steel" is refining and summarizing about the regularity in combat, that is the embodiment of Chinese traditional philosophy characteristics "Dao". "Dao" is namely the road, can be extended into law. Martial arts "dao" characteristic can seen in that time and later writings about the martial arts. The famous "Yue nv talking about swordfight" in $<$ Wu Yue Chun Qiu $>$ just reflects the tendency of Chinese wushu seeking tao. She offered "When fighting with others, one should be peaceful outside and be spiritual inside. The man who understands Tao, one can act as one hundred, and one hundred can act as ten thousands." The famous evaluation in <Chuang tzu •talking about the sword> "the way of using sword " [5] is a summary of the way of martial arts too. "Tao" is an important characteristic of Chinese traditional philosophy, and the martial arts of pre-Qin period had been such characteristics preliminarily. Third, the cultural performance of Chinese martial arts from the "iron" into "steel" is its tendency of "attaching importance to moral". "Lao tze advocates Tao, Confucius advocates morality". According to history carries, the education of Confucius on student's "shooting" and "defense" reflects the holistic view "Morality and arts cultivation". "One man without Xin, Lian, Ren or Yong doesn't accord with moral standards and can not learn martial arts or talk about sword." [6] said in $<$ Shih Chi $>$ also reflects the importance of "Morality" when one man learn martial arts. We can see from the above that Chinese martial arts began to have the tendency of attaching importance to "Morality". Fourth, Lao tze's thought of "Dare not become host and become guest, dare not go forward one inch and backward one feet" and "Taking the defense as an offense" in military, and Mo zi's thought of "Non attack and be good at defense" should make the martial arts develop towards the cultural characteristics of defense. The prosperous culture of pre-qin dynasty affects the martial arts in many aspects, which makes Chinese martial arts from a fight technology, develop into a certain Chinese cultural characteristics.

The Secularization of Song-Ming Neo-Confucianism Makes Martial Arts Gradually Develop into a Mature Culture Carrier. The feudal ruling class, in order to maintain its authoritarian rule, had adopted a policy of fooling the people and making people weak for a long time, artificially enhanced people's harmonious and obedient state, which made the culture worshiping prevail and to a great extent, restricts the rapid development of martial arts. In such a social environment, in the traditional consciousness, gradually formed the concept that took martial arts as a" low skill". Martial arts more developed in the lower people. It is difficult to integrate into the upper circle of culture, at the same time, the traditional culture belong to of the upper society also was harder to integrate into martial arts. Late in the feudal society, the rise of Song-Ming Neo-Confucianism prompted the comprehensive expression of martial arts, which was one of the main reasons that the martial arts and martial arts culture become comprehensive mature in Ming and qing dynasties. First of all, Chinese martial arts made energetic spirit of the traditional culture embody more clearly. If the pre-qin culture began to make the martial arts become into "steel" from "iron", then, the traditional culture with all-round downward during the Ming and qing dynasties have smelted martial arts become a highly flexible fine steel, which is the so-called " hard and soft martial art technique ". Affected by this spirit of energetic and promising, each of wushu sorts of Quan almost pays attention to " hard and soft martial art technique ". Taijiquan is the best manifest of this spirit. By the argument above, martial arts has incisively and vividly reflected this spirit of energetic and promising with traditional culture full of dialectics thoughts, this is one of laws of the art of attack and defence in wushu "Technology coming into 'Dao"[7]. Second, "Tao" of Chinese martial arts gets full embodiment. The characteristics of "Tao" as early as the pre-qin period affected Chinese martial arts. Song-Ming Neo-Confucianism more comprehensively and profoundly affected the martial arts. Tang Shunzhi < Martial arts choreography>, $\mathrm{Yu}$ DaYou < Sword Scriptures>, wu Shu <Hand-arm Record>, Cheng Chongdou <Fighting Technology After Farming $>$ and so on are all wonderful summary, which profoundly embody the characteristics of "Ttao" of the Chinese traditional culture. Third, that martial arts advocates "morality" becomes more specific. The pre-qin period, influenced by mainly Confucianism culture, martial arts 
had had the tendency of the "Morality and Art Cultivation". With the secularization of neo-confucianism, morality worshiping almost become the primary problem of each wushu branches. "Before learn kungfu, one must cultivate his virtues first" [8] has become a common specification in the field of martial arts. In addition, that the characteristics of traditional culture pays great attention to "harmony" has gradually become the main technical essentials and spiritual pursuit of martial arts. That Chinese traditional culture moved down made Chinese traditional philosophy thoughts "Nature and Man in One" get incisively and vividly. Martial arts requires the overall harmony on whole body, inside and outside, proceeding from one point to another and so on, which is the concrete embodiment of the traditional concept of " Nature and Man in One " [9] of Chinese martial arts. Martial arts pursues the harmony between people against people, and also embodies its defensive culture characteristics, which form the sharp contrast with the west. Lao tze urged " Assisting one man with Tao", rather than "Conquering world with arms", even "having to use martial arts", and strive to "win without using martial arts". The military thoughts of Lao tze has deeply influenced the martial arts in the process of its secularization. Each of schools of martial arts developed during the Ming and qing dynasties does not advocate to flaunt its superiority and to provoke others, but for the purpose of defense. The wushu practicers in China rarely travel around the world, like Russia's strongman, Japan ronin, look for a person to contest. what's more, in the unbearable circumstances, they have to fight with the offenders.

\section{The Situation and Hope of Wushu Culture}

Western sports thought in the process of continuous publicity, constantly, tearing up the idea of our national traditional sports, changing the martial arts from the traditional model, training mode and method, to the update of the martial arts culture idea. Looking back the development of wushu in a century, "modern martial arts, athletics martial arts" has become a trademark of the Chinese martial arts. The culture thoughts "feeling, cultivate one's morality, self-entertainment" of "nature and man in one" in martial arts culture are gradually marginalized. The diversity of contents and forms of the martial arts is being entombed and replaced by new single martial arts developed under the guidance of western sports. Martial arts have been shocked. In fact, not only in the cities, but also in the countryside Chinese martial arts gradually lost their market. The young men pursuit the fresh sensory of western culture, at the same time, they show the unprecedented indifference to our national culture, let alone, understand China's national culture by learning WuShu. And what makes us feel disappointed and sad is that all of these traditional wushu decline in a different degree today.

\section{The Foreign Martial Arts Impact on Chinese Wushu}

The foreign martial arts such as taekwondo, karate, kendo, etc, with its distinctive national and cultural characteristics and the form of easy to learn are loved and followed by the masses of teenagers. <Foshan daily> reports the grand occasion of taekwondo development in Foshan city title as "The city of martial arts brings about taekwondo hot". The title as "the city of martial arts" let a person can only recall past glory of martial arts in foshan. The teenagers and even old people has strong interest in taekwondo. To experience the charm of oriental culture and learning means of physical, self-defense from sports of South Korea brings Chinese traditional martial arts into a dilemma in the city. What is more shocking is < China youth daily> titled as "Chinese martial arts is kicked out urban fashion by taekwondo" [10] reported the impact of taekwondo on Chinese martial arts, and let us see the grand occasion of taekwondo in China, especially in Beijing, Shanghai and other cities throughout the country, and the traditional martial arts can only be taught and practiced in the streets, parks, temples and other places. When we are intoxicated with the longing moment of Chinese martial arts into the Olympics, we should spend big strength in the study, refining, packaging and promotion of martial arts, otherwise, the ancient and profound martial arts can only be " side dishes " in contemporary Chinese sports culture and is difficult to be compared with classic elegant main dishes. 


\section{Summary}

The extensive and profound Chinese martial arts has a long history. In the process of thousands of years of development by the influence and impact of Chinese culture, it has become national treasures with unique cultural characteristics from a simple practical combat art. Jus like traditional Chinese medicine, traditional opera, calligraphy, Chinese painting, Chinese martial arts is the carrier of Chinese traditional culture, contains rich culture characteristics. In the social tide of national culture inheritance, carrying forward the national spirit, to deeply analyze the martial arts culture characteristics, not only promotes the development of wushu itself, at the same time, to have a positive effect to finish the era mission of country and people.

\section{Acknowledgements}

The National social Science Fund (12BTY046); 2015Philosophy and Social Science Fund Project of Hunan province (15YBA318); 2015Scientific Research Key project of Hunan Province Department of Education (15A154); 2015Western philosophy and Social science Fund project of Hunan province (15YBX037); 2013 Scientific Research Project of Hunan province Department of Education (13C768); 2014 Core Curriculum group Construction Projects of General Class of Jishou University.

\section{References}

[1] Yang Jianying, Abstraction and Analysis of Culture Connotation of Wushu [J], Journal of Shenyang Sport University, Vol.34, No.5, PP.136-139.

[2] Wang Jing, the Effects of Chinese Traditional Culture on Wushu Virtue [J], Journal of Xian Physical Education Institute, Vol12, PP.28-30.

[3] Wang Guibing, The Confucian Way of Doing Things [M], Bejing, press of the tides, 2012, PP.117.

[4] Pan Shuren, Confucius home Language [M], Beijing, Citic Publishing House, 2014, PP.34.

[5] Qiao Fengjie, Cultural Symbol [M], Beijing, Social Sciences Academic Press, 2014, PP.19.

[6] Si Maqian, Figures complete Biography in Historical Records, 4 biographies [M], Beijing, Beijing times Chinese Publishing house, 2014, PP. 1791.

[7] Li Shutong, Li Shutong Talking about Arts [M], Changsha, Hunan University Publishing House, 2011, PP.195.

[8] Zhe Lan, Chinese Traditional Culture [M], Beijing, National Administrative College press, 2013, PP.153.

[9] Song Yilin, the Essential ideas of The Confucian-Dao [M], Guangzhou: Sun yat-sen University Press, 2014, PP.157.

[10] Qiu Pixiang, Research on Chinese wushu Culture Inheritance and Education [M], Beijing: Higher Education Press, 2011, PP.76. 